\title{
Dipenyleneiodonium Induces Growth Inhibition of Toxoplasma gondii through ROS Induction in ARPE-19 Cells
}

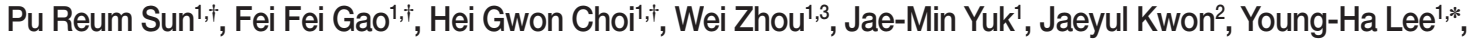 \\ Guang-Ho Cha, ${ }^{1, *}$ \\ ${ }^{1}$ Department of Medical Science \& Infection Biology, Chungnam National University, School of Medicine, Daejeon 34134, Korea; ${ }^{2}$ Department of

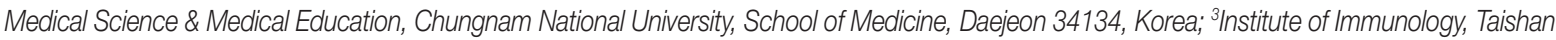 \\ Medical College, Tai'an 271-000, Shandong, China
}

\begin{abstract}
Based on the reactive oxygen species (ROS) regulatory properties of diphenyleneiodonium (DPI), we investigated the effects of DPI on host-infected T. gondii proliferation and determined specific concentration that inhibit the intracellular parasite growth but without severe toxic effect on human retinal pigment epithelial (ARPE-19) cells. As a result, it is observed that host superoxide, mitochondria superoxide and $\mathrm{H}_{2} \mathrm{O}_{2}$ levels can be increased by DPI, significantly, followed by suppression of $T$. gondii infection and proliferation. The involvement of ROS in anti-parasitic effect of DPI was confirmed by finding that DPI effect on T. gondii can be reversed by ROS scavengers, $\mathrm{N}$-acetyl-L-cysteine and ascorbic acid. These results suggest that, in ARPE-19 cell, DPI can enhance host ROS generation to prevent $T$. gondii growth. Our study showed DPI is capable of suppressing $T$. gondii growth in host cells while minimizing the un-favorite side-effect to host cell. These results imply that DPI as a promising candidate material for novel drug development that can ameliorate toxoplasmosis based on $\mathrm{ROS}$ regulation.
\end{abstract}

Key words: T. gondii, reactive oxygen species, diphenyleneiodonium, N-acetyl-L-cysteine, ARPE-19 cell

\section{INTRODUCTION}

Toxoplasma gondii is one of the most widely spread protozoal infection and intracellular parasite, which infects all the warmblooded animals, including approximately $30 \%$ of the human population. Infection is generally asymptomatic, but immunocompromised humans, such as those who are infected during pregnancy, can cause severe illness, such as chorioretinitis, convulsions, hydrocephalus, and stillbirth [1].

When T. gondii reaches the eye, an inflammatory reaction occurs. This inflammatory lesion progresses to retinitis and involves the choroid secondarily [2]. The human retinal pigment epithelium (hRPE) is located in the portion of the most external of retina segment which exist a monolayer, and it has roles as blood retina barrier and is essential for retinal homeostasis,

- Received 30 October 2018, revised 5 March 2019, accepted 14 March 2019.

*Corresponding authors (yhalee@cnu.ac.kr; gcha@cnu.ac.kr)

${ }^{\dagger}$ These authors contributed equally to this work.

(c) 2019, Korean Society for Parasitology and Tropical Medicine

This is an Open Access article distributed under the terms of the Creative Commons Attribution Non-Commercial License (http://creativecommons.org/licenses/by-nc/4.0) which permits unrestricted non-commercial use, distribution, and reproduction in any

medium, provided the original work is properly cited. development, survival, and physiological activity of photoreceptor. Because of its the importance in infection and inflammation in visual system, ARPE-19 cell infected with T. gondii was used as a model to investigate the toxoplasmic retinochoroiditis, and the regulatory mechanisms of $T$. gondii invasion and proliferation.

Previous studies have shown that reactive oxygen species (ROS) plays a crucial role as a second messenger in normal cell growth processes and cell cycling [3,4], and also ROS have been known molecules of intracellular signaling cascade. The appropriate levels of ROS act as a signal transducer, while continuous exposure or high levels ROS can trigger dysfunction of $\mathrm{RPE}$, increased cellular signaling, and apoptosis [5]. The retina is especially vulnerable to oxidant-generating damage, and oxidative stress is regarded as an important development of agerelated RPE cell degeneration, functional disorder, and loss [6].

In this regard, diphenyleneiodonium (DPI) has been used to inhibit ROS production mediated by various flavoenzymes, including NADH: ubiquinone oxidoreductase, NADPH oxidase [7], nitric-oxide synthase, xanthine oxidase, and NADPH cytochrome P450 oxidoreductase [8]. In particular, DPI has 
been commonly used as an inhibitor of NADPH oxidase in various type of cells. However, it also has been reported that DPI can induce ROS production and thus, enhance oxidative stress with Japanese encephalitis virus (JEV) infection [9], which suggest the presence of unknown, opposite effect of DPI depending on cell types.

In the present study, we investigated the effect of DPI on the generation of intracellular ROS in ARPE-19, and suggested a mechanism to inhibit $T$. gondii infection rate and intracellular proliferation. Our results show that DPI might be one promising candidate in the development of methods which to prevent, ameliorate or cure toxoplasmosis.

\section{MATERIALS AND METHODS}

\section{Host cell culture}

ARPE-19 cell line, obtained from American Type Culture Collection (ATCC, Manassas, Virginia, USA), was cultured in a 1:1 mixture of Dulbecco's Modified Eagle's Medium (DMEM/ F12) with $10 \%$ fetal bovine serum (FBS), and $1 \%$ antibioticantimycotic (Gibco, Grand Island, New York, USA) at $37^{\circ} \mathrm{C}$ in a $5 \% \mathrm{CO}_{2}$ incubator up to $70 \%$ confluence.

\section{Toxoplasma gondii culture}

Tachyzoites of $T$. gondii RH strain that expresses transgenic green fluorescent protein (GFP-RH) were kindly provided by Dr. Yoshifumi Nishikawa (Obihiro University of Agriculture and Veterinary Medicine, Japan). Tachyzoites were maintained on ARPE19 cell line and incubated at $37^{\circ} \mathrm{C}$ and $5 \% \mathrm{CO}_{2}$ for 2 to 3 days.

\section{Toxoplasma gondii intracellular growth assay}

ARPE-19 cells were seeded in 12 or 24 well plates with coverslips and serum-starved for $4 \mathrm{hr}$ prior to T. gondii (GFP-RH) infection or indicated amount of DPI, NAC, and ascorbic acid treatment. In order to determine $T$. gondii proliferation in APRE-19 cells, the cell was infected with T. gondii at a multiplicity of infection of 5 tachyzoites per cell $(\mathrm{MOI}=5)$, and fluorescent images were obtained by a confocal laser scanning microscope (Leica TCS SP5, Wetzlar, Hesse-Darmstadt, Germany) or fluorescence microscopy. After infection or treated chemicals the coverslips were washed with PBS and then fixed with $4 \%$ formaldehyde overnight at $4{ }^{\circ} \mathrm{C}$.

Cells were stained with Texas Red ${ }^{\circledR}-\mathrm{X}$ phalloidin (Life Technologies Corporation, Carlsbad, California, USA) to label Factin and mounted with mounting solution with DAPI (Vector
Laboratories, Burlingame, California, USA) to stain nucleus The number of parasites per vacuole was counted from a part taken randomly. The experiment was repeated for 3 times.

\section{Measurement of ROS}

To analyze the levels of ROS production in ARPE-19 cells under experiments conditions. Cells were co-treated with or without DPI, NAC and ascorbic acid (all form Sigma-Aldrich, Saint Louis, Missouri, USA) for $4 \mathrm{hr}$. ROS level was measured using specific ROS detecting fluorescent probes, dihydroethidium (DHE, Merck KGaA, Darmstadt, Germany), 5-(and-6)chloromethyl-2', 7'-dichlorodihydrofluorescein diacetate, acetyl ester (DCFDA, Life Technologies, Carlsbad, California, USA) and mitochondrial superoxide indicator (MitoSOX Red, Thermo Fisher Scientific, Waltham, Massachusetts, USA). Following washing with warm PBS, ARPE-19 cells were incubated with DHE, DCFDA, or MitoSOX for $30 \mathrm{~min}$ at $37^{\circ} \mathrm{C}$ in dark. The stained cells were imaged using a Zeiss HXP 120-V laser-scanning microscope (Göttingen, Germany), or Confocal microscopy (Leica). Each of the fluorescence intensity of all images were taken using the same exposure time. The fluorescence intensity was measured by flow cytometry and the cellular images were captured using laser scanning confocal microscope.

\section{Flow cytometry analysis}

ARPE-19 Cells were treated with DPI, NAC and ascorbic acid for $4 \mathrm{hr}$ after starvation and then were detached with Trypsin-EDTA (Gibco), re-suspended in a fresh culture medium, and stained intracellular ROS detection with DHE or MitoSOX for $30 \mathrm{~min}$ at $37^{\circ} \mathrm{C}$. The samples were then subjected to flow cytometric analysis using a BD Canto II Flow cytometer (BD Biosciences, San Jose, California, USA) and Flow Jo software (Treestar, Ashland, Oregon, USA). For each sample, 5,000-30,000 cells were analyzed. The results were presented as means \pm standard deviation (SD) of 3 independent experiments. The experiment was repeated for 5 times.

\section{Western blot analysis}

Western blot was carried out as described previously [10], treated cells were lysed on ice for $30 \mathrm{~min}$, after boiling, equal amounts of denatured proteins were separated by SDS-PAGE and transferred onto PVDF membranes and probed with the relevant antibodies. The primary antibodies used were mouse anti-TP3 and $\alpha$-tubulin (Santa Cruz Biotechnology, Dallas, Texas, USA). 
Statistical analysis

Results were repeated at least 3 independent times and expressed as the mean $\pm S D$. $P$-values between groups were determined by a 2 -tails paired Student $t$-tests. $P<0.05$ was considered statistically significant.

\section{RESULTS}

\section{DPI increases intracellular ROS in ARPE-19 cells}

In order to determine the effect of DPI on host intracellular ROS, the change of intracellular ROS (superoxide and $\mathrm{H}_{2} \mathrm{O}_{2}$ ) in DPI-treated ARPE-19 cells was monitored by using DHE,

\section{A

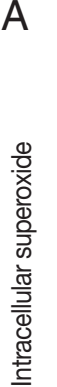
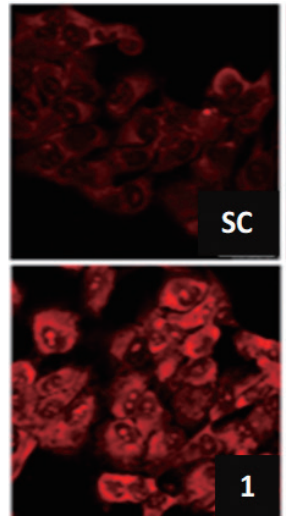

B
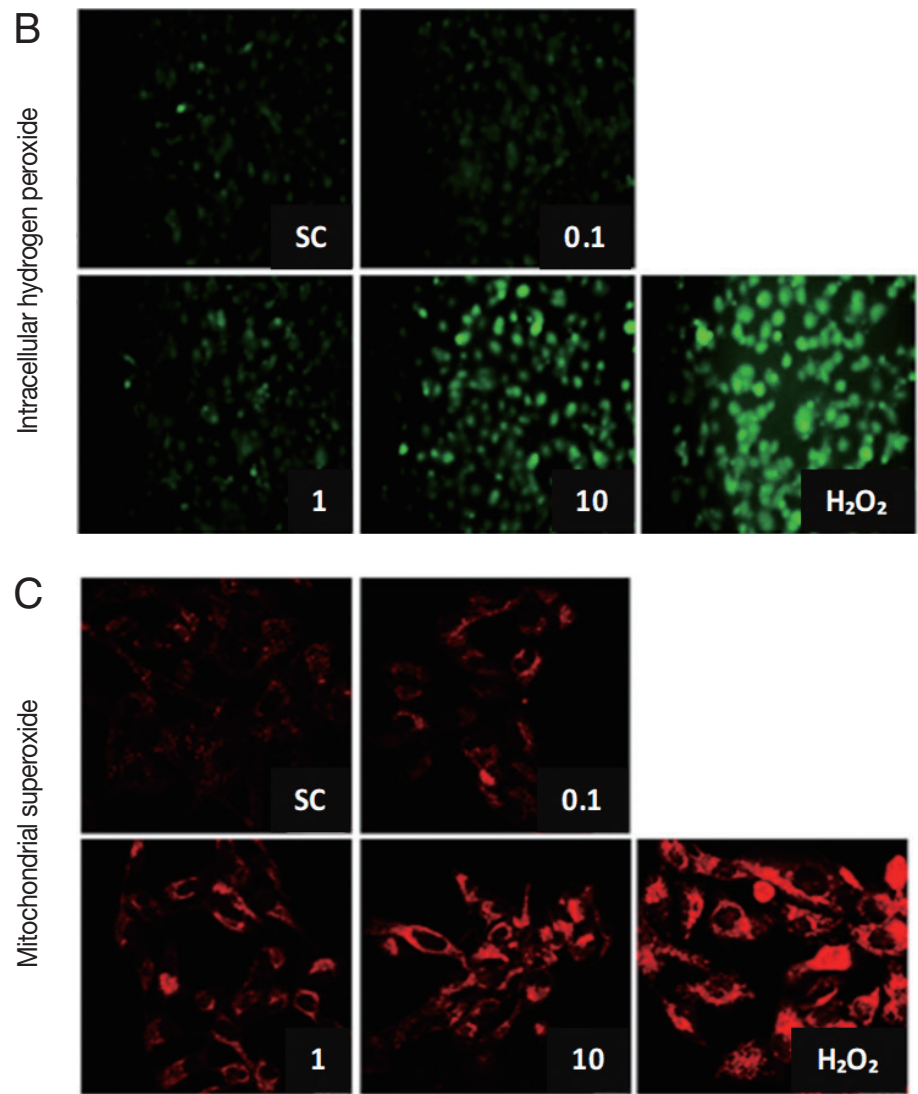
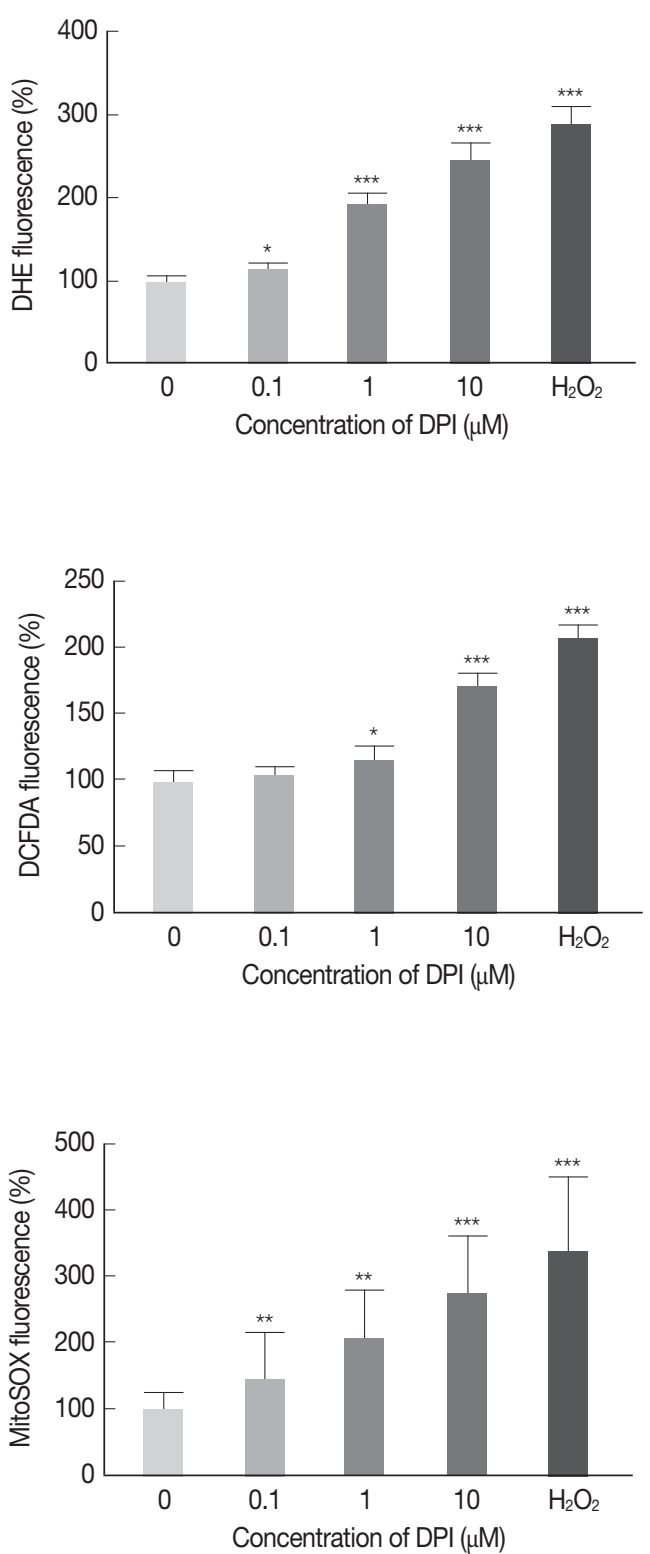

Fig. 1. DPI increases intracellular ROS level in ARPE-19 cells. ARPE-19 cells were deprived of serum for $4 \mathrm{hr}$ and then treated with the indicated concentration of DPI $(0,0.1,1$, and $10 \mu \mathrm{M})$ or $\mathrm{H}_{2} \mathrm{O}_{2}(500 \mu \mathrm{M})$ for $4 \mathrm{hr}$. Intracellular ROS generated was measured by $(\mathrm{A}, \mathrm{C}) \mathrm{la}-$ ser scanning confocal microscope images, or (B) fluorescence microscope images with (A) DHE (10 $\mu \mathrm{M}, 30 \mathrm{~min}$ ) for superoxide (Red),

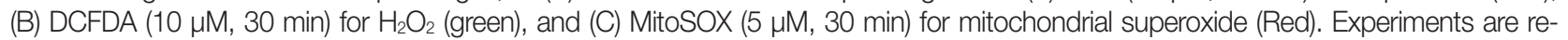
peated at least 3 times (2-tailed student's test). SC, solvent control. ${ }^{\star} P<0.05,{ }^{\star \star} P<0.01,{ }^{* \star *} P<0.001$. 
MitoSOX, and DCFDA, respectively.

The DPI treatment to ARPE-19 cells clearly increased the fluorescence intensities of DHE, DCFDA, and MitoSOX in a dose dependent manner, but without cell shape alteration or DNA aggregation in DAPI stained nucleus (Fig. 1). These findings suggest that in ARPE-19 cells DPI is a strong ROS inducer as $\mathrm{H}_{2} \mathrm{O}_{2}$, but without inducing cell death (Fig. 1).

Flow cytometry was applied to confirm the results from microscopic observation. The FSC-SSC plot showed that $10 \mu \mathrm{m}$ DPI treatment had no significant effect on cell size (FSC) and cell density (SSC) compared to DPI untreated group (data not shown). The histograms from flow cytometry analysis showed the median intensity of DHE, DCF-DA and MitoSOX in ARPE19 cells after 4 hr DPI treatment induced significant increase of host intracellular ROS without vital status change of host cells (Supplementary Fig. S1). In accordance with previous microscopic observation, cells treated with $10 \mu \mathrm{m}$ DPI showed approximately 2-fold increase of all types of ROS, compare to the untreated control groups (Supplementary Fig. S1).

Taken together, these results suggest that, at the specific concentration, DPI can be used as a potent intracellular ROS inducer and anti-parasitic agent without excessive host cytotoxicity in ARPE-19 cells.

\section{DPI has suppression effect on T. gondii infection and proliferation in ARPE-19 cells}

Next, we investigated whether DPI can suppress T. gondii infection and proliferation in ARPE-19 cells, in accordance with host intracellular ROS level change.

As shown in Fig. 2A, there is no significant difference of the infection rate between DPI-untreated group and low concentrations $(0.1$ and $1 \mu \mathrm{m})$, however, in $10 \mu \mathrm{m}$ DPI treated group the infection rate was remarkably suppressed. In addition, high dose of DPI showed noticeable inhibitory effect on intracellular T. gondii growth compared to DPI-untreated cells. These data suggest that short time (4 hr) with high DPI concentration $(10 \mu \mathrm{m})(\mathrm{ST}-\mathrm{HC})$ treatment of DPI can markedly suppress both $T$. gondii infection rate and growth.

Next, we applied different treatment methods of DPI, that ARPE-19 cells infected with T. gondii, then treated with DPI at low concentration $(0.1$ and $1 \mu \mathrm{m})$ for long time (24 hr) (LTLC) (Supplementary Fig. S2A). The data showed that $0.1 \mu \mathrm{m}$ DPI with $24 \mathrm{hr}$ did not significantly affect both $T$. gondii infection and proliferation compared to the control group, and more than $40 \%$ tachyzoites replicated 3 times to produce 8 parasites per parasitophorous vacuole (PV). However, $1 \mu \mathrm{m}$ DPI treatment led to significant restriction of intracellular parasites proliferation, most PVs had only 2 or 4 tachyzoites. In addition, in $10 \mu \mathrm{m}$ DPI treated cells, only less than 10\% replicated 3 times in $24 \mathrm{hr}$. We also examined the T. gondii infection ratio represented by percentage of infected cells to total cells, and found that low concentrations DPI had no effect on the infection ability of T. gondii. But with high concentration DPI, most parasites failed to invasion into host cell.

In previous experiments, we observed that DPI treatment can suppress intracellular T. gondii infection and proliferation (Fig. 2A, Supplementary Fig. S2A). However, it was difficult to distinguish whether the inhibition effect of DPI on infection rate and intracellular growth of $T$. gondii is host cell-mediated indirect event or the chemical agent's direct effect on T. gondii itself. Therefore, isolated T. gondii was treated with DPI for 2 $\mathrm{hr}$, and then the DPI-treated parasites were infected to the host cells for 1-2 hr. $0.1 \mu \mathrm{m}$ DPI had no effect on T. gondii infection and growth, but in $1 \mu \mathrm{m}$ and $10 \mu \mathrm{m}$ DPI treated T. gondii, both the infection rate and intracellular proliferation rate were significantly reduced compared to the untreated control group (Supplementary Fig. S2B). The RT-PCR and western blot data also showed that DPI treatment reduced T. gondii SAG1 mRNA level and TP3 protein level (Supplementary Fig. S2D).

In summary, it was confirmed that "direct method" (DPI-toparasite) has better T. gondii infection prevention capability than "indirect method" (DPI - to- host cell), but for inhibition of T. gondii proliferation, "indirect method" was more effective (Fig. 2B, Supplementary Fig. S2C).

\section{NAC and ascorbic acid reduced DPI-increased intracellular ROS in ARPE-19 cells}

Based on our previous findings (Figs. 1, 2), it was presumed that the inhibition of the infection rate and intracellular proliferation of T. gondii by DPI might be caused by DPI-induced intracellular ROS production. We hypothesized that antioxidants could reduce the elevated ROS by DPI treatment and rescue the T. gondii infection rate and intracellular growth.

From a preliminary experiment, it is found that $\mathrm{H}_{2} \mathrm{O}_{2}$-induced ROS was reduced by treatment with NAC and ascorbic acid. Similarly, endogenous ROS was reduced by both agents and more reduction was observed by ascorbic acid than NAC with microscopy and FACS (Supplementary Fig. S3).

Next, it was examined whether DPI-induced ROS generation can be suppressed by NAC and ascorbic acid. The result 
A
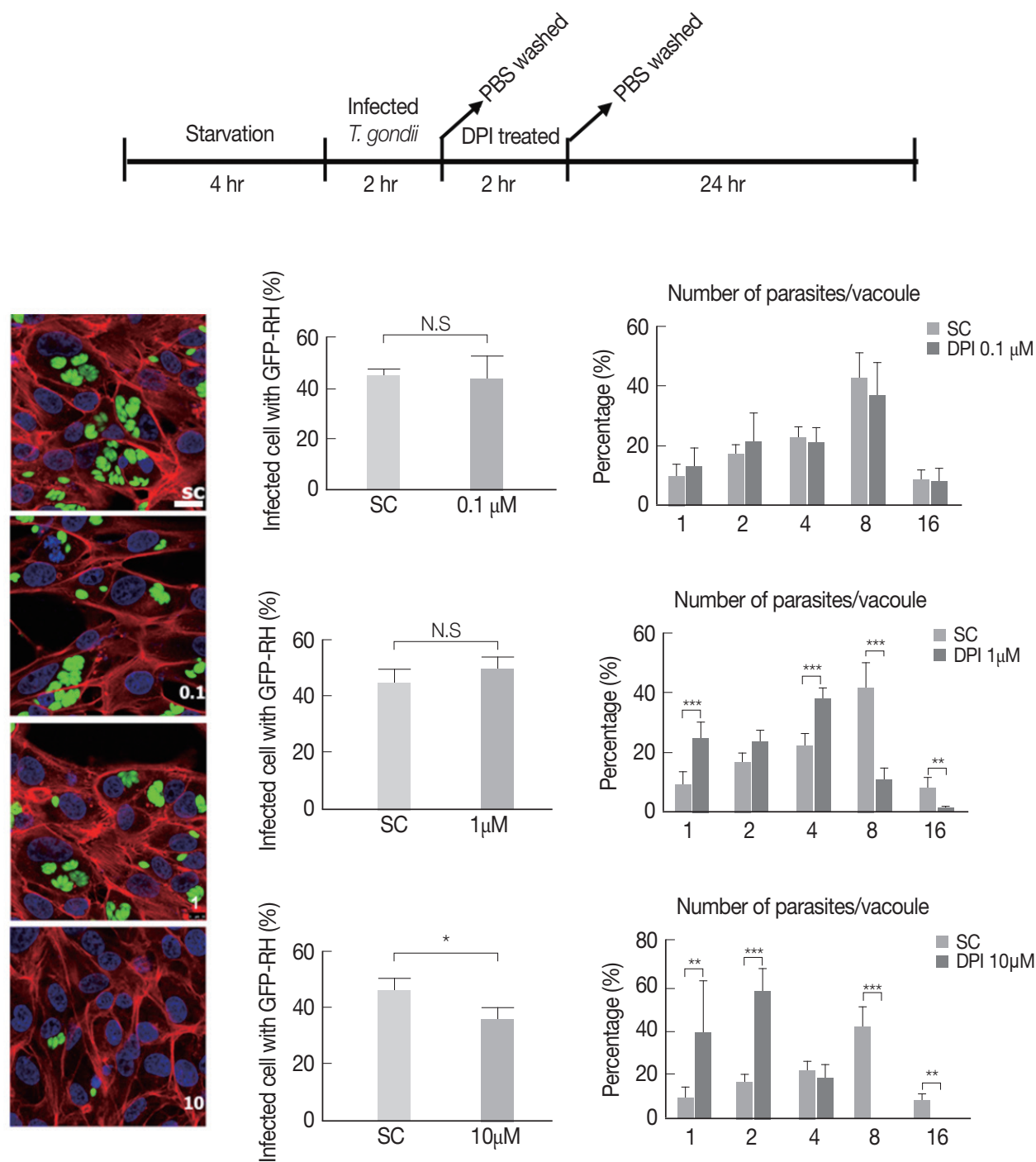

B
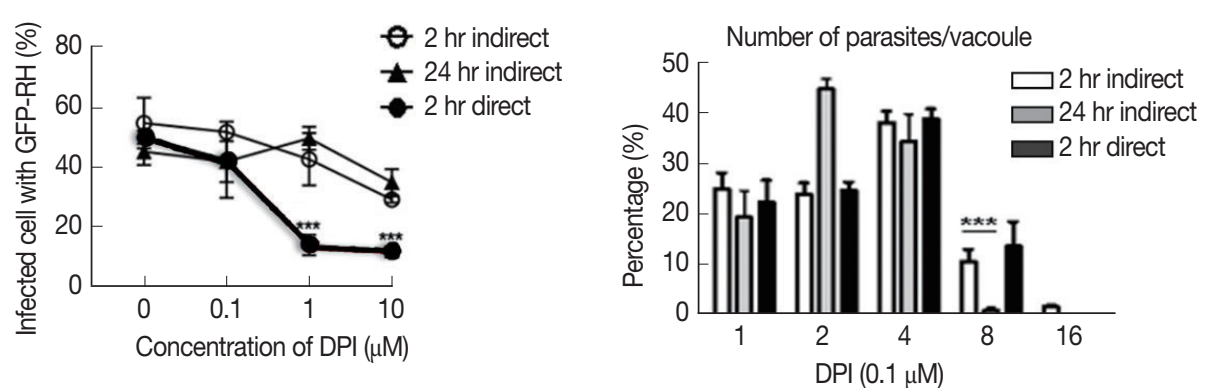

Fig. 2. DPI suppressed T. gondii proliferation and infection in ARPE-19 cells. (A) ARPE-19 cells infected with $T$. gondii for $2 \mathrm{hr}$ and then treated with the indicated concentration of DPI $(0,0.1,1$, and $10 \mu \mathrm{M})$ for $24 \mathrm{hr}$. (B) Host cells were infected with DPI-treated T. gondii or infected with fresh T. gondii and then treated with DPI. Cells were fixed and stained with Texas Red ${ }^{\circledR}-\mathrm{X}$ phalloidin and DAPI for labeling Factin (red) and nuclear DNA (blue), respectively. The number of parasites per vacuole and the number of infected host cells were counted and converted to percentage. Scale bar: $10 \mu \mathrm{m}$. SC, solvent control. ${ }^{\star} P<0.05$, ${ }^{\star *} P<0.01,{ }^{\star \star *} P<0.001$. Experiments are repeated at least 3 times (2-tailed student's test). N.S, means no significant difference. 
A
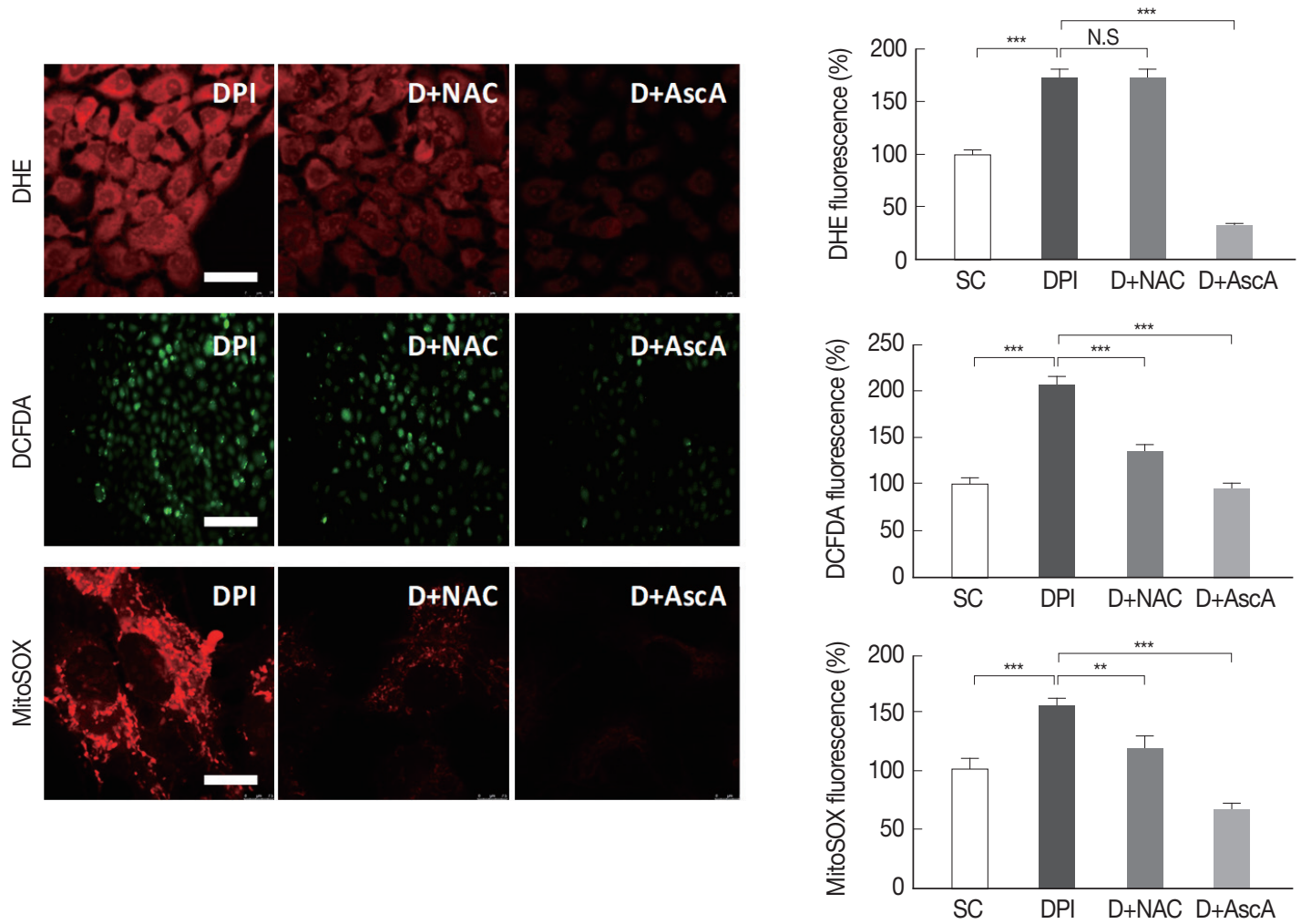

B
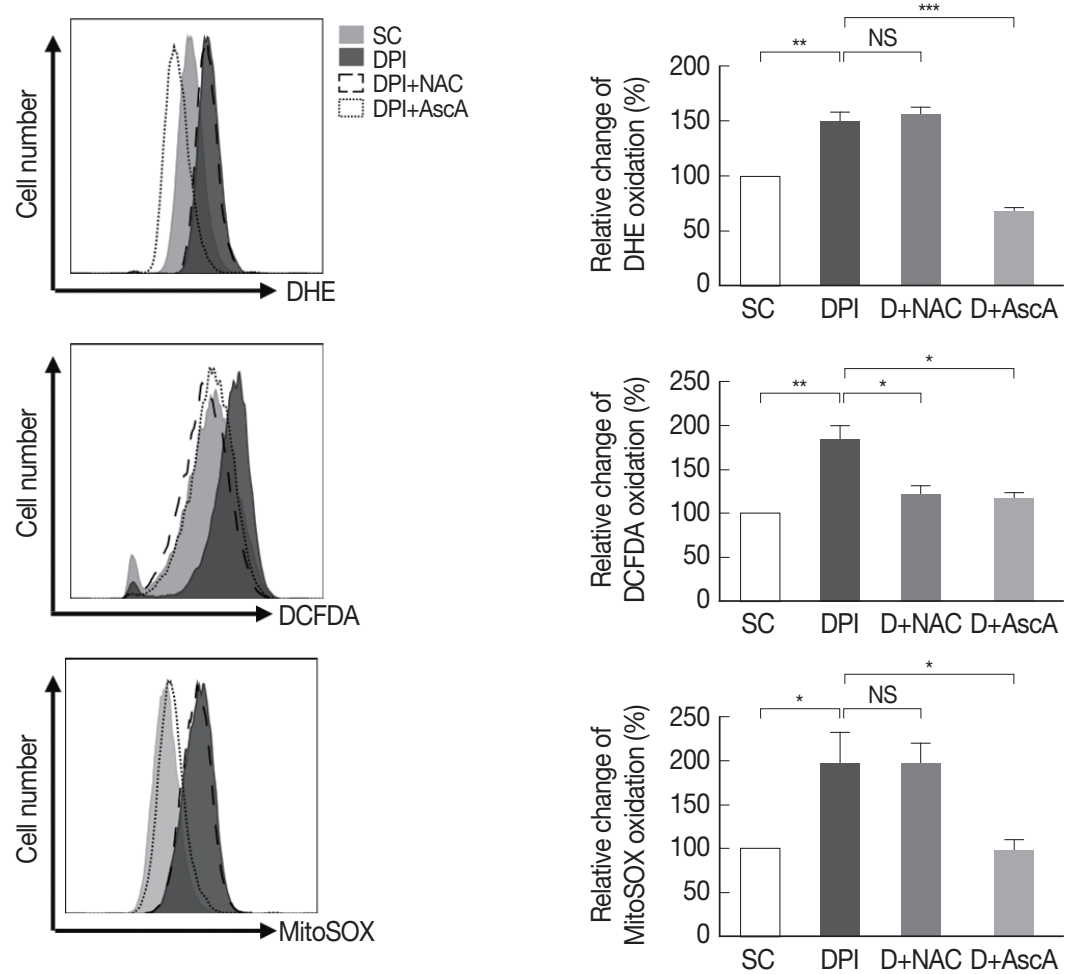

Fig. 3. NAC and ascorbic acid reduced DPI-increased intracellular ROS in ARPE-19 cells. ARPE-19 cells were deprived of serum for 4 $\mathrm{hr}$ then were treated with DPI $(10 \mu \mathrm{M})$ in the presence or absence of NAC or ascorbic acid for $4 \mathrm{hr}$. (A) Microscopy or (B) flow cytometry were performed to measure ROS level. Experiments are repeated at least 3 times (2-tailed student's test). SC, solvent control. * $P<0.05$, ${ }^{\star \star} P<0.01,{ }^{\star \star *} P<0.001$, NS: no significant difference. Scale bar: DHE: $25 \mu \mathrm{m}$, DCFDA: $150 \mu \mathrm{m}$, MitoSOX: $10 \mu \mathrm{m}$. 
A
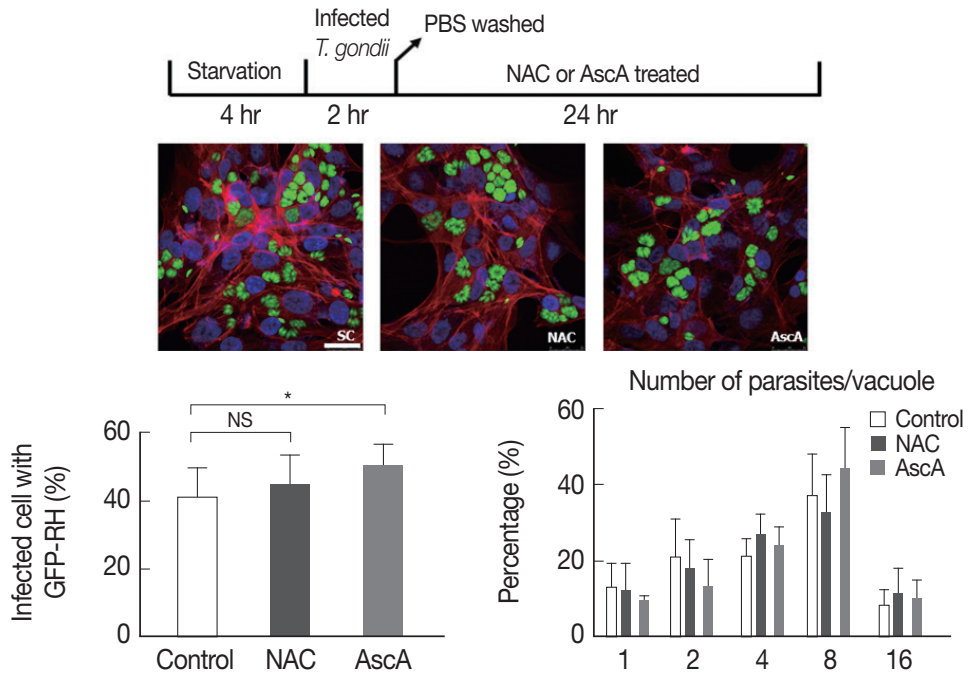

B

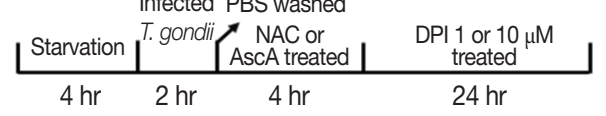

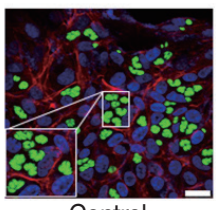

Control

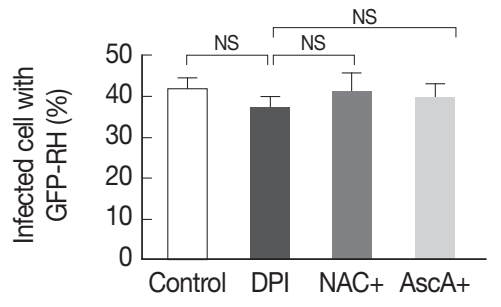

C

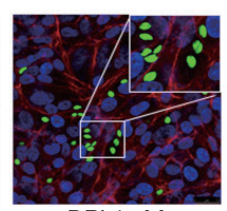

$\mathrm{DPI} 1 \mu \mathrm{M}$

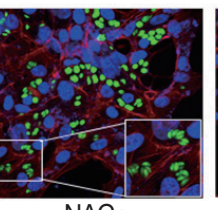

$\mathrm{NAC}+$

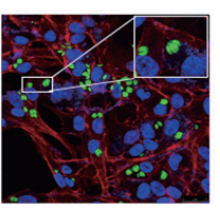

AscA+
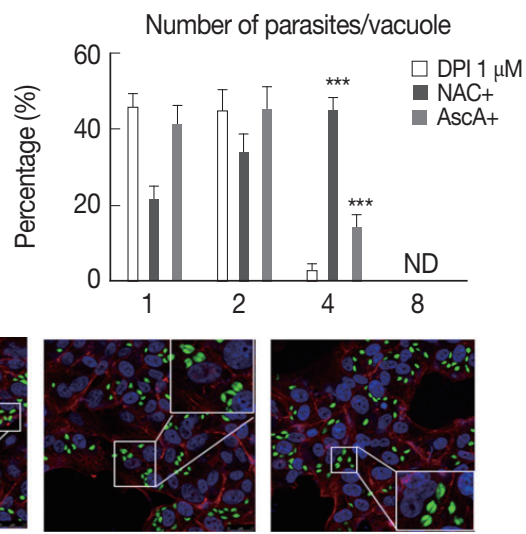

AscAt
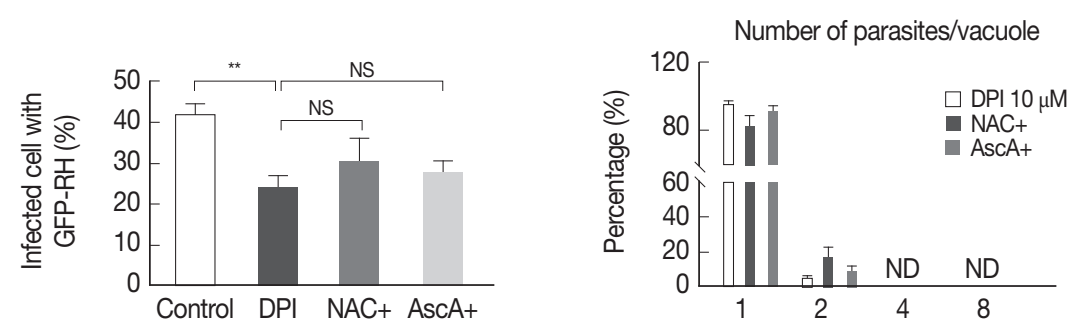

Fig. 4. Pretreatment NAC and ascorbic acid can partially recover DPI-suppressed proliferation of $T$. gondii. Serum starved $4 \mathrm{hr}$ cells were infected with T. gondii (GFP-RH strain) at MOI5 for $2 \mathrm{hr}$, and then, extracellular tachyzoites were immediately removed by washing with PBS, cells were incubated with (A) NAC $(5 \mu \mathrm{M})$ or ascorbic acid $(100 \mu \mathrm{M})$ for $24 \mathrm{hr}$, or $(\mathrm{B}, \mathrm{C})$ pre-treated with NAC $(5 \mu \mathrm{M})$ or ascorbic acid $(100 \mu \mathrm{M})$ for $4 \mathrm{hr}$ and stimulated with DPI (1 or $10 \mu \mathrm{M})$. Cells were fixed and stained with Texas Red ${ }^{\circledR}$-X phalloidin for F-actin (red), and DAPI for nuclear DNA (blue), respectively. Counting of parasites in PV was carried out after parasite infection. SC, solvent control. ${ }^{*} P<0.05,{ }^{* *} P<0.01,{ }^{* \star *} P<0.001$. Scale bar: $10 \mu \mathrm{m}$. 
showed that NAC had no effect on DPI-induced ROS, but ascorbic acid had significant effect on suppression of DPI-induced ROS. It was confirmed that when ascorbic acid treated to host cells, intracellular ROS level became even lower than the control group (Fig. 3).

\section{DPI-induced T. gondii proliferation suppression was partially rescued by pretreatment of NAC and ascorbic acid}

Since NAC and ascorbic acid reduced the DPI-induced intracellular ROS level in ARPE-19 cells, we hypothesized that DPIinduced suppression of $T$. gondii infection and proliferation can be caused by host ROS increase and NAC and ascorbic acid can reverse the effect.

To test whether NAC and ascorbic acid have a self-effect on T. gondii, we observed the effect of NAC and ascorbic acid on the T. gondii infection and growth. As shown in Fig. 4A, the effect of NAC on the T. gondii infection rate in DPI-free condition was negligible, however, ascorbic acid showed tendency to increase the infection rate compared to the control group. Neither NAC nor ascorbic acid had distinct effect on the T. gondii proliferation rate.

Next, in order to confirm our hypothesis, NAC or ascorbic acid were pretreated to ARPE-19 cells as determined and the T. gondii infection and proliferation were observed (Fig. 4B). As a result, in the presence of $1 \mu \mathrm{m}$ DPI, most parasites did not divide or just replicated 1 time to produce 2 parasites per PV, only less than $5 \%$ divided 2 times, however, pretreatment with NAC, more than $40 \%$ of PVs had 4 tachyzoites, and pretreatment with ascorbic acid, almost 20\% PVs had 4 tachyzoites. The observations indicate that, NAC and ascorbic acid are able to restore the intracellular replication of $T$. gondii even in the presence of $1 \mu \mathrm{m}$ DPI (Fig. 4B). For high-dose DPI (10 $\mu \mathrm{m})$, even pretreating with NAC and ascorbic acid did not rescue the T. gondii growth that most of the PVs had only 1 or 2 tachyzoites. This result might have occurred due to the limited ROS scavenging capability of NAC and ascorbic acid compare to the ROS generating ability of $10 \mu \mathrm{m}$ DPI (Fig. 4C).

\section{DISCUSSION}

In this study, the biological effect of DPI on protozoan parasite, T. gondii, was examined to verify whether DPI can inhibit the T. gondii infection and the intracellular growth in host retinal pigment epithelium cells. For the experiments, 2 types of DPI treatment methods were tested: one is ST-HC treatment and the other is LT-LC treatment. The logic behind these 2 applications is that for an acute infection of T. gondii, or in other words, high load infection of T. gondii, like sepsis, there must be severe damage in the human body including inflammation and therefore, finding of effective concentration (high dose) of DPI to suppress $T$. gondii growth and remove the parasites from human body in short time would be critical. To the contrast, when mild infection of T. gondii occurs, it is preferable to treat low-dose DPI (but still with anti-T. gondii effect) to reduce the possibility of unexpected side effects, for example, possible host cell cytotoxicity of DPI. In addition, a constant supply of low-dose DPI might be also useful as a preventive method for our body to protect from $T$. gondii infection at the very beginning of infection process. The experimental results confirmed that both treatment conditions can successfully inhibit the $T$. gondii infection and proliferation in ARPE-19 cell.

In the view of inhibiting T. gondii invasion and growth in host cell, both DPI treatment conditions showed clear preventive performances, which implicated that the DPI could be a promising candidate for anti-T. gondii drug. But as discussed above, side-effect of chemical material is another important considerable matter in determining the effective treatment dose of the chemical material and therefore, host cell viability was examined with high dose DPI, and it is found that maximum dose of DPI indeed have some cytotoxicity to host cell. Cytotoxic effect of DPI has been reported in the experiments with specific cell lines, which showed that $320 \mathrm{~nm}$ DPI can reduce mouse embryonic stem cell viability via increased apoptotic signals [11]. But there were also other reports that higher concentration of DPI (100 $\mu \mathrm{m})$ was required to induce cytotoxicity [12]. These reports suggest sensitivity to DPI is different from cell to cell. According to our data, in ARPE-19 cell, we suggest that 1 to $10 \mu \mathrm{m}$ is a proper concentration range to use DPI in suppressing T. gondii infection and growth, but without host cytotoxicity.

While testing the anti-parasitic effect of DPI, another question came to surface that whether the anti-T. gondii effect of DPI is host cell-mediated mechanism or not. Various host cell defense mechanisms have been reported which removes the infiltrated pathogens in the host cells, including ROS production, autophagy, and endolysosomal destruction [13]. DPI may have induced these events in host cells to inhibit the infiltration or proliferation of infected T. gondii. But because DPI is a small molecule that can penetrate or be absorbed through the membranes of organisms or organelles, there is a possibility that extracellular DPI may reach into intracellular $T$. gondii 
and act directly on it to suppress $T$. gondii's vital activities. This aspect that DPI might inhibit $T$. gondii infection even without host cell machinery can provide another usage of the chemical as a preventive medicine, for example, targeting free $T$. gondii tachyzoites in blood stream at the very early stage of infection.

The experimental results showed that indirect method is more effective in suppressing infected parasites growth, but the direct method works better in preventing T. gondii infiltration into host cell. Because the invasion process is an essential part for the proliferation of T. gondii in host cells, direct effect of DPI on free T. gondii can be considered as a valuable aspect in designing effective strategy for inhibiting or even preventing $T$. gondii proliferation in human host (Fig. 2).

DPI has been shown to reduce intracellular superoxide formation by inhibiting NADPH oxidase $[7,8,14]$. However, there is also opposite results reported $[9,15]$ and according to our data, in APRE-19 cells, it is found that DPI rather increases intracellular ROS level which is consistent with the report that there was enhance in ROS level from ARPE-19 cells treated with DPI for $24 \mathrm{hr}$ [15]. It also reported that when embryonic mouse hypothalamus cell line (N11 cell) was incubated with DPI, a significant production of ROS was detected and the induction of ROS generation by DPI needs the time necessary for the pentose phosphate pathway (PPP) flux and Glutathione (GSH) level to decrease significantly. With the treatment of DPI, the glutathione/glutathione disulfide ratio decreased and the efflux of glutathione out of the cells decreased [16]. These results imply that DPI effect on ROS regulation can be different depending on cell type.

Especially, for the induction of ROS by DPI, 2 explanations are possible. One possibility is that DPI inhibition of NADPH oxidase caused "rebound" effect that, in order to compensate the loss of ROS, host cell may have started to synthesize other classes of ROS producing enzymes or reduce the production of ROS scavenging proteins [17]. Another possibility is that DPI might be acting on component of electron transport system in mitochondria. There is a supportive report that shows DPI can elevate mitochondrial ROS production via an inhibition of the mitochondrial respiratory chain [12].

Another interesting finding was that anti-ROS agents, NAC and ascorbic acid showed selective inhibitory effect on DPI. Both NAC and ascorbic acid are well-known ROS scavengers and both agents successfully suppressed the $\mathrm{H}_{2} \mathrm{O}_{2}$ induced intracellular ROS. But when the NAC and ascorbic acid were tested against DPI-induced intracellular ROS, NAC was not ca- pable of reducing DPI-induced ROS. Because NAC and ascorbic acid both clearly reversed the DPI effect on T. gondii growth, it implies the presence of different DPI-inducible parasite control mechanisms in addition to ROS.

For developing the usage of DPI as a preventive drug for toxoplasmosis, another possible treatment option which need to be test is that whether pretreatment of DPI to host cell will induce augmentation of host defense against $T$. gondii infection and proliferation. As mentioned above, if free tachyzoites which survived all the attacks from immune system and DPI, then the next sequence will be anchoring to host cell surface and invasion. Therefore, in the view of host cell, if DPI can induce various anti-pathogenic cellular events before T. gondii arrives, the effectiveness of host defense against $T$. gondii will be increased.

As a conclusion, it is confirmed that DPI can inhibit T. gondii infection and proliferation in ARPE-19 cell, and that the inhibitory mechanism is based on enhanced production of host intracellular ROSs, such as superoxide, $\mathrm{H}_{2} \mathrm{O}_{2}$, and mitochondrial superoxide, by DPI. In addition, through the series of the designed experiments, cell based-ocular toxoplasmosis model was established which enables the small molecule-screening for chemical suppressors for $T$. gondii growth or proliferation. These data will provide useful information in developing candidate material for anti-T. gondii drugs.

\section{ACKNOWLEDGMENTS}

This work was supported by the Basic Science Research Program of the National Research Foundation of Korea funded by the Ministry of Education, Science, and Technology (NRF2013R1A1A2062046) (NRF-2018R1D1A1B07050779), by the Research Fund of Chungnam National University, by the Korea Health Technology Research \& Development Project, Ministry of Health \& Welfare, Republic of Korea (A100876), and by the Natural Science Foundation of Shan Dong Province, China (ZR2015HQ033) and the National Natural Science Foundation of China (81701575).

\section{CONFLICT OF INTEREST}

The authors declare no conflict of interest related to this study. 


\section{REFERENCES}

1. Tenter AM, Heckeroth AR, Weiss LM. Toxoplasma gondii: from animals to humans. Int J Parasitol 2000; 30: 1217-1258.

2. Park YH, Nam HW. Clinical features and treatment of ocular toxoplasmosis. Korean J Parasitol 2013; 51: 393-399.

3. Cai J, Nelson KC, Wu M, Sternberg P Jr, Jones DP. Oxidative damage and protection of the RPE. Prog Retin Eye Res 2000; 19: 205-221.

4. Espinosa A, Henríquez-Olguín C, Jaimovich E. Reactive oxygen species and calcium signals in skeletal muscle: a crosstalk involved in both normal signaling and disease. Cell Calcium 2016; 60: 172-179.

5. Birben E, Sahiner UM, Sackesen C, Erzurum S, Kalayci O. Oxidative stress and antioxidant defense. World Allergy Organ J 2012; 5: 9-19.

6. Woods JR Jr, Plessinger MA, Fantel A. An introduction to reactive oxygen species and their possible roles in substance abuse. Obstet Gynecol Clin North Am 1998; 25: 219-236.

7. Massart C, Giusti N, Beauwens R, Dumont JE, Miot F, Sande JV. Diphenyleneiodonium, an inhibitor of NOXes and DUOXes, is also an iodide-specific transporter. FEBS Open Bio 2013; 4: 5559.

8. Szilagyi JT, Mishin V, Heck DE, Jan YH, Aleksunes LM, Richardson JR, Heindel ND, Laskin DL, Laskin JD. Selective targeting of heme protein in cytochrome $\mathrm{P} 450$ and nitric oxide synthase by diphenyleneiodonium. Toxicol Sci 2016; 151: 150-159.

9. Sharma M, Sharma KB, Chauhan S, Bhattacharyya S, Vrati S, Kalia M. Diphenyleneiodonium enhances oxidative stress and inhibits Japanese encephalitis virus induced autophagy and ER stress pathways. Biochem Biophys Res Commun 2018; 502: 232237.
10. Zhou W, Quan JH, Gao FF, Ismail HAHA, Lee YH, Cha GH. Modulated gene expression of Toxoplasma gondii infected retinal pigment epithelial cell line (ARPE-19) via PI3K/Akt or mTOR signal pathway. Korean J Parasitol 2018; 56: 135-145.

11. Kučera J, Binó L, Štefková K, Jaroš J, Vašíček O, Večeřa J, Kubala L, Pacherník J. Apocynin and diphenyleneiodonium induce oxidative stress and modulate PI3K/Akt and MAPK/Erk activity in mouse embryonic stem cells. Oxid Med Cell Longev 2016; 2016: 7409196.

12. Li N, Ragheb K, Lawler G, Sturgis J, Rajwa B, Melendez JA, Robinson JP. DPI induces mitochondrial superoxide-mediated apoptosis. Free Radic Biol Med 2003; 34: 465-477.

13. Clough B, Wright JD, Pereira PM, Hirst EM, Johnston AC, Henriques R, Frickel EM. K63-linked ubiquitination targets Toxoplasma gondii for endo-lysosomal destruction in IFN $\gamma$-stimulated human cells. PLoS Pathog 2016; 12: e1006027.

14. Li Y, Trush MA. Diphenyleneiodonium, an NAD(P)H oxidase inhibitor, also potently inhibits mitochondrial reactive oxygen species production. Biochem Biophys Res Commun 1998; 253: 295-299.

15. Park SE, Song JD, Kim KM, Park YM, Kim ND, Yoo YH, Park YC. Diphenyleneiodonium induces ROS-independent p53 expression and apoptosis in human RPE cells. FEBS Lett 2007; 581: 180-186.

16. Riganti C, Gazzano E, Polimeni M, Costamagna C, Bosia A, Ghigo D. Diphenyleneiodonium inhibits the cell redox metabolism and induces oxidative stress. J Biol Chem 2004; 279: 47726-47731.

17. Stowe DF, Camara AK. Mitochondrial reactive oxygen species production in excitable cells: modulators of mitochondrial and cell function. Antioxid Redox Signal 2009; 11: 1373-1414. 
A

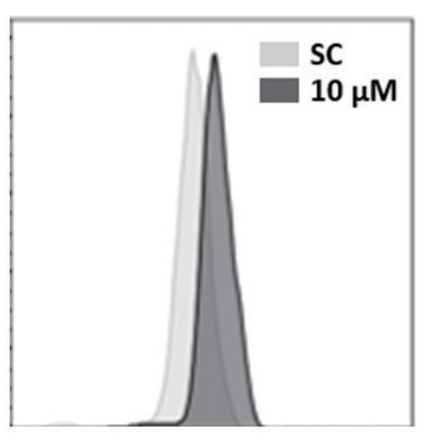

B

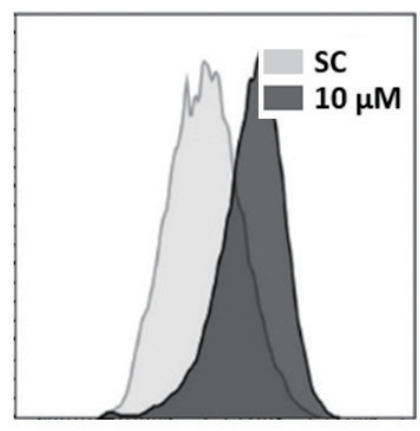

C

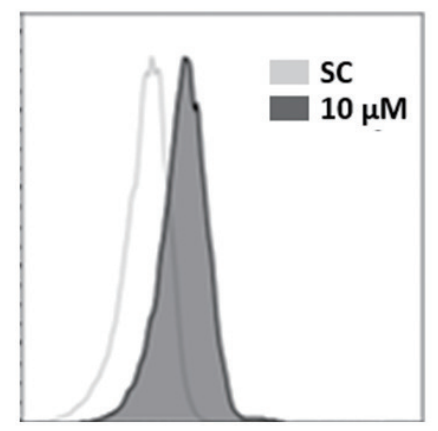

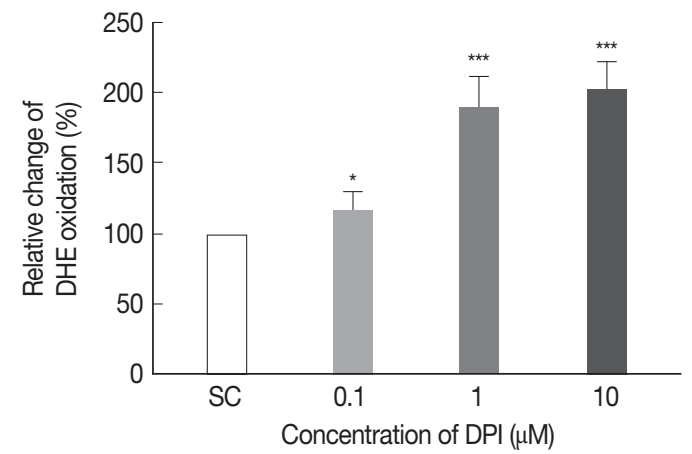
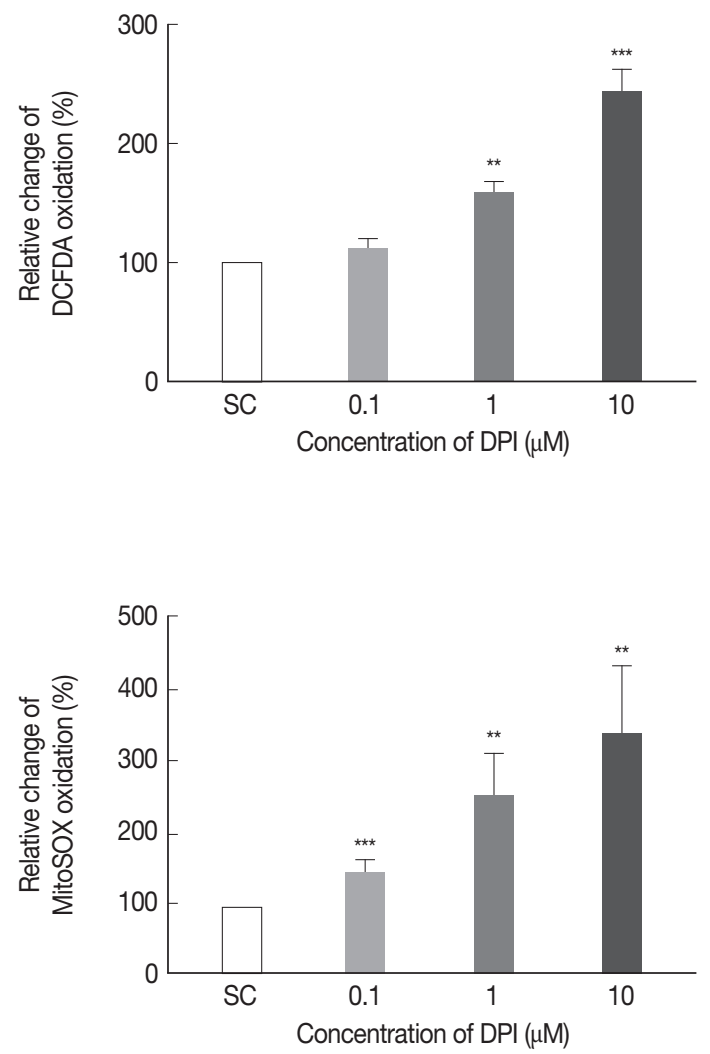

Supplementary Fig. S1. DPI increases intracellular ROS level in ARPE-19 cells. ARPE-19 cells were deprived of serum for $4 \mathrm{hr}$ and then treated with the indicated concentrations of $\mathrm{DPI}(0,0.1,1$, and $10 \mu \mathrm{m})$ or $\mathrm{H}_{2} \mathrm{O}_{2}(500 \mu \mathrm{m})$ for $4 \mathrm{hr}$. Intracellular ROS generation was

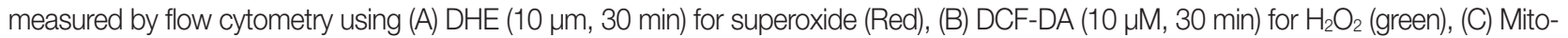
SOX (5 $\mu \mathrm{m}, 30 \mathrm{~min}$ ) for mitochondrial superoxide (Red). Experiments are repeated at least 3 times (2-tailed student's test). ${ }^{*} P<0.05$, ${ }^{* *} P<0.01,{ }^{* \star *} P<0.001$. vs untreated DPI; SC: solvent control. 
A
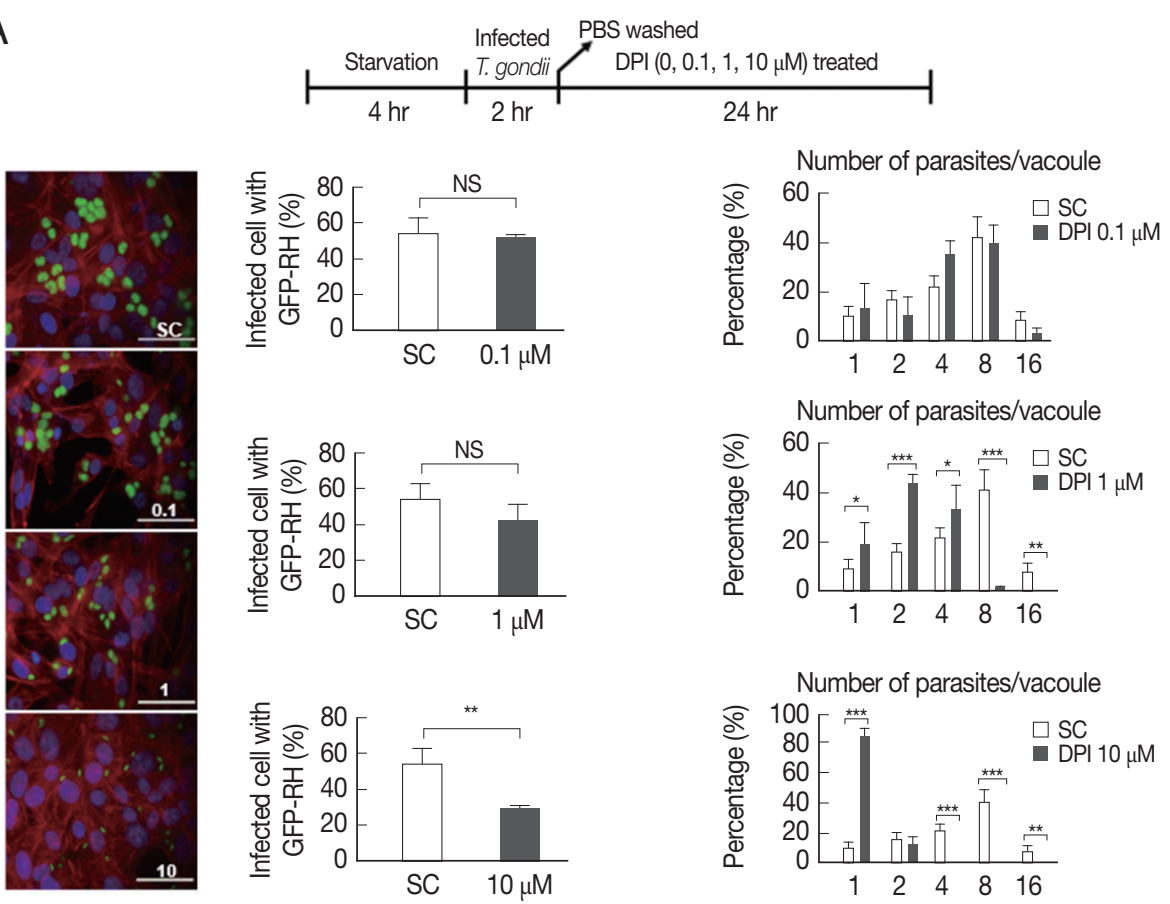

B
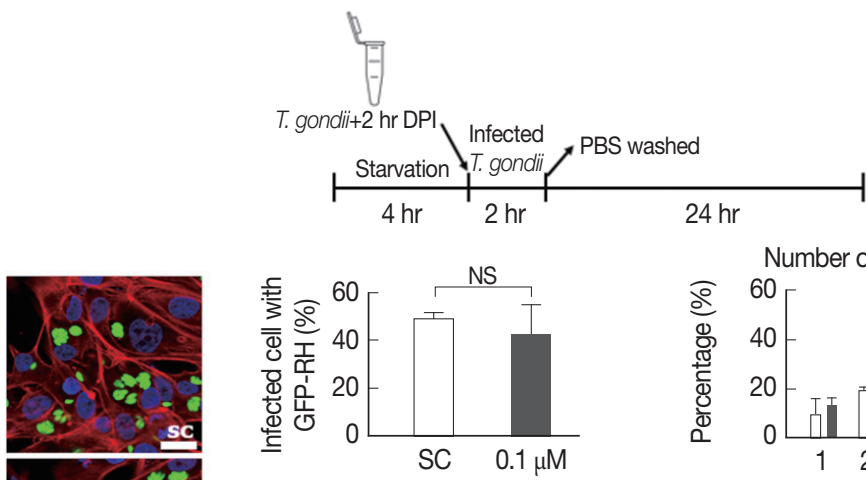

Number of parasites/vacoule
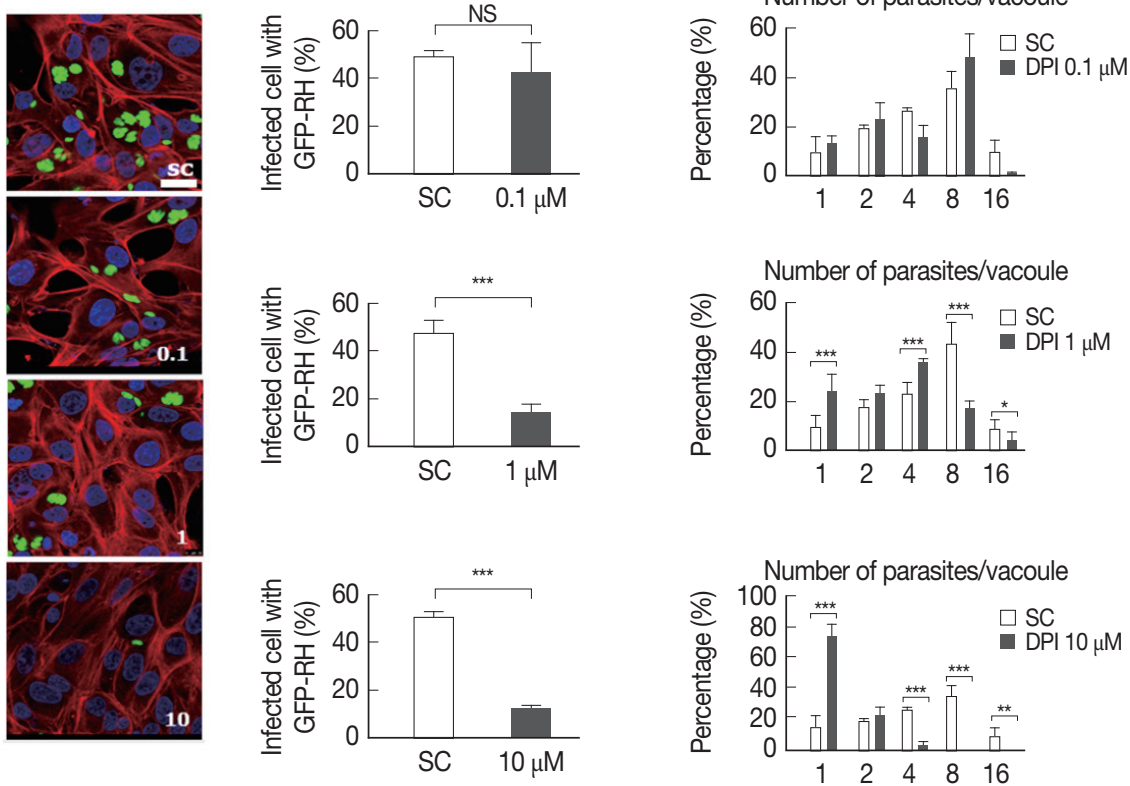

Supplementary Fig. S2. DPI has suppression effect on T. gondii proliferation and infection in ARPE-19 cells. The T. gondii growths in ARPE-19 cells were measured by fluorescence microscopy. (A) The ARPE-19 cells were infected by T. gondii and then treated with different concentrations of DPI $(0,0.1,1$, and $10 \mu \mathrm{M})$, and (B) the host cells were infected with DPI-treated T. gondii. The number of infected cells by T. gondii and the number of parasites per vacuole were counted and from DPI-treated T. gondii converted to percentage. 
C

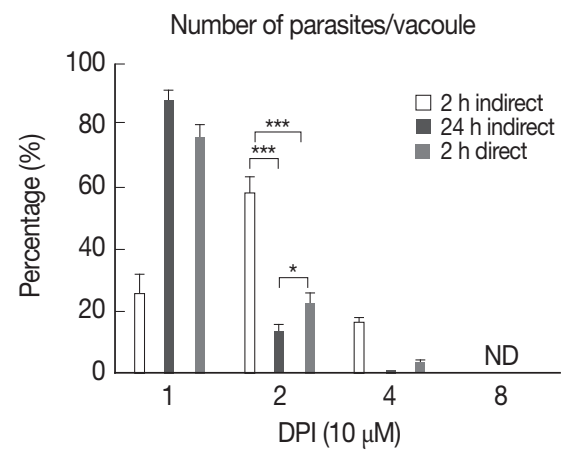

$\mathrm{D}$

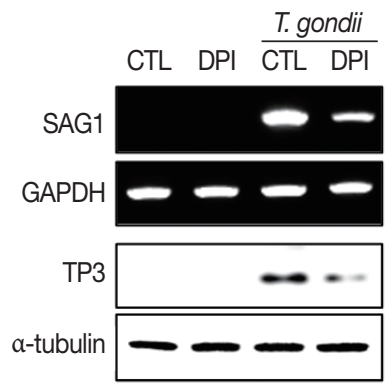

Supplementary Fig. S2. Continued. (C) ${ }^{*} P<0.05,{ }^{* *} P<0.01,{ }^{* * *} P<0.001$. (D) RT-PCR and western blot were performed to measure $T$. gondii infection level. Experiments are repeated at least 3 times (2-tailed student's test). 
A
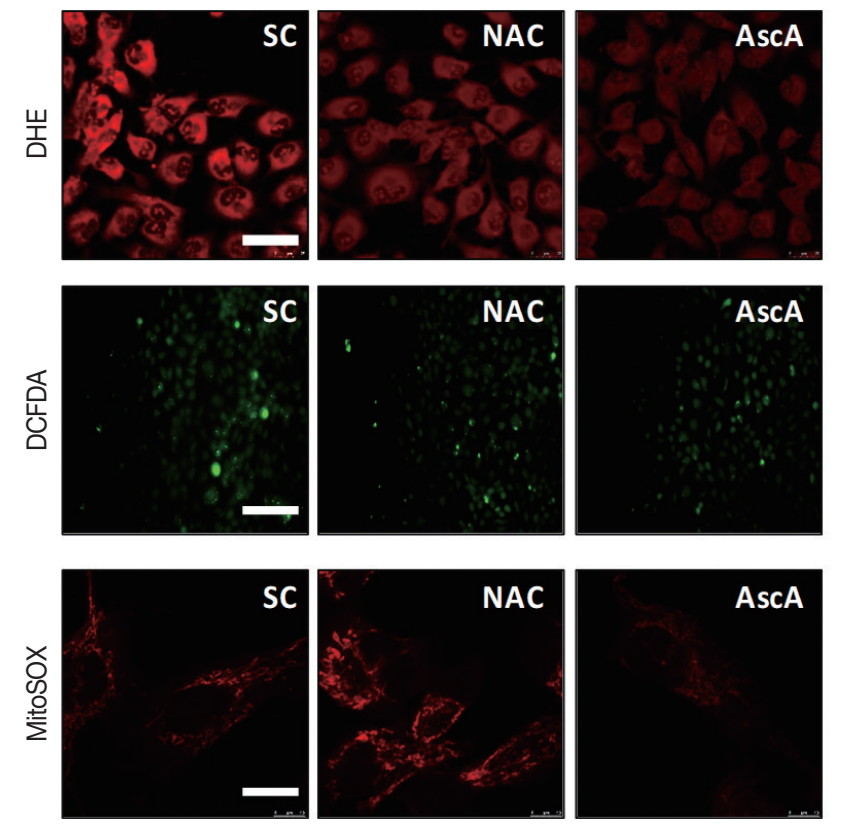
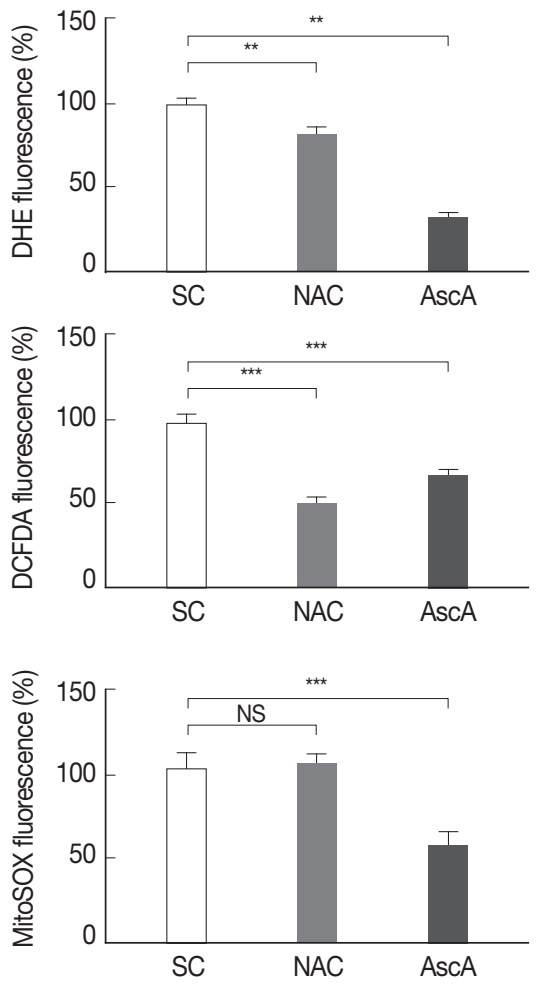

$\mathrm{B}$
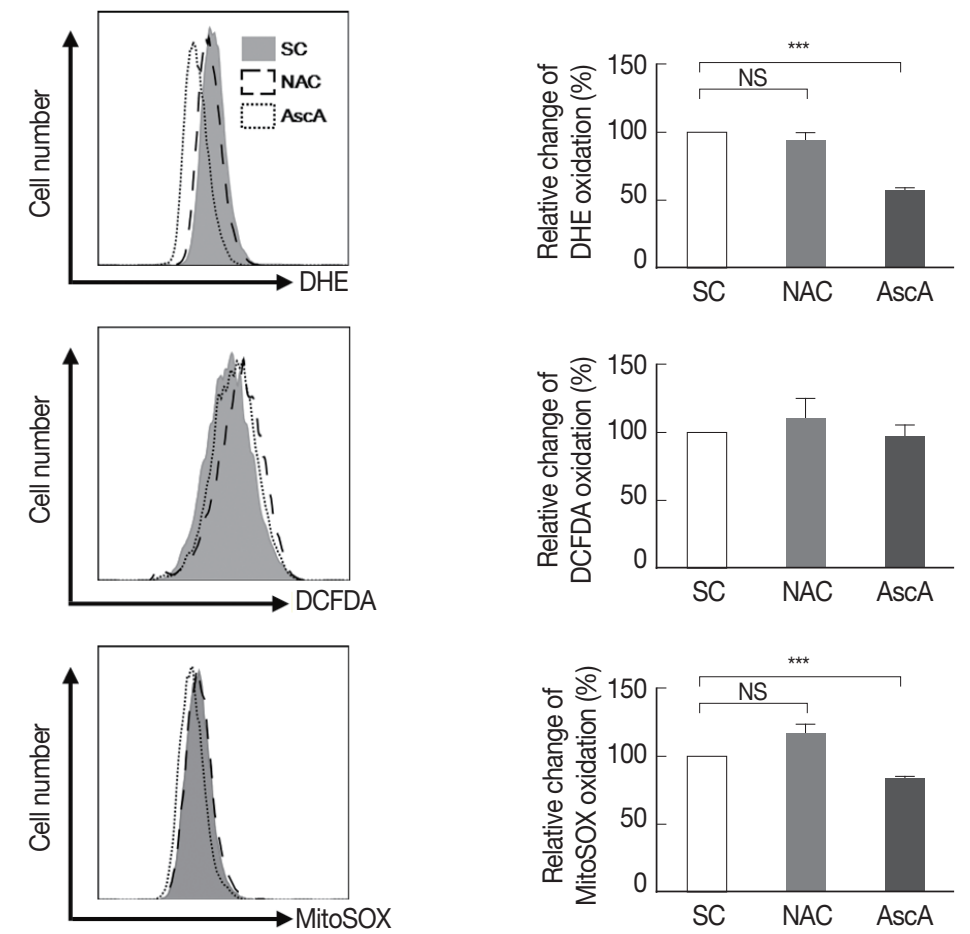

Supplementary Fig. S3. NAC and ascorbic acid reduced DPI-increased intracellular ROS in ARPE-19 cells. ARPE-19 cells were deprived of serum for $4 \mathrm{hr}$ then were treated with DPI $(10 \mu \mathrm{m})$ in the presence or absence of NAC or ascorbic acid for $4 \mathrm{hr}$. (A) Microscopy or (B) flow cytometry were performed to measure ROS level with DHE, DCFDA or MitoSOX. Experiments are repeated at least 3 times (2-tailed student's test). ${ }^{*} P<0.05,{ }^{* *} P<0.01,{ }^{* \star *} P<0.001$. NS: no significant difference; SC: solvent control; Scale bar: DHE: $25 \mu \mathrm{m}$, DCFDA: $150 \mu \mathrm{m}$, MitoSOX: $10 \mu \mathrm{m}$. 